INTERNATIONAL DESIGN CONFERENCE - DESIGN 2018

https://doi.org/10.21278/idc.2018.0467

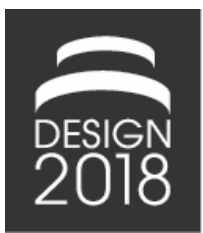

\title{
EARLY PHASE EVALUATION OF ADDITIVE MANUFACTURING TECHNOLOGIES WITHIN AN INTEGRATED PRODUCT AND PRODUCTION ENGINEERING APPROACH
}

\author{
J. Kaspar, P. Stoffels, J.-H. Schneberger and M. Vielhaber
}

\begin{abstract}
Today, an essential challenge lies in a holistic as well as integrated assessment and selection of an adequate manufacturing technology bearing in mind a tailored product design along with a further optimized material selection, particularly with respect to the emerging potentials of the increasingly industrialized application of additive manufacturing (AM). Therefore, this contribution presents a scientifically detailed view on a methodological set-based product and production engineering approach dealing with technical, economic and ecological aspects in an aggregated, tool-based manner.
\end{abstract}

Keywords: additive manufacturing, production process selection, integrated product development, decision making, early design phase

\section{Introduction and motivation}

Apart from the eponymous materials often defining bygone ages throughout history (Ashby, 2011), also technologies have always been one of the defining elements of human history (e.g., the industrial revolution stages from mechanization and steam power in the 18th century to mass production, automation, and nowadays artificial intelligence and information technology of cyber-physical systems). Thus, and referring to the actual manufacturing perspective of a fourth industrial revolution, the evolving age of additive manufacturing (AM) assumes an increasing strategic importance (e.g., in medical, aerospace, but gradually also automotive industries) even with regard to the emergence of ondemand manufacturing (The Economist, 2012). Nevertheless, AM processes do not only provide benefits, for example, in case of a unique selling proposition (USP), a substantial simplification of familiar process chains as well as a considerable increase of geometric flexibility (e.g., previously common manufacturing restrictions such as intricate contours, undercuts, or cavities) including an enormous material efficiency, all without any additional manufacturing costs (Gibson et al., 2010; Bromberger and Kelly, 2017). Extended cycle times as well as higher costs per part for large-scale and high-volume industrial series production constitute the reverse of the medal since $3 \mathrm{D}$ printing features a volume-driven process. Additionally, some challenges arise in the process control and reliability of the still young technology, i.e., the comprehensive field of materials analysis and characterization (e.g., process-related effects within the individual material, but also entire work piece), the associated dimensional tolerance, and ultimately its process-driven and application-oriented engineering design. Consequently, the increased competition between additive and subtractive (e.g., CNC machining) technologies is more than ever a focus of attention, irrespective of how the latter pointing out significant benefits with regard to process stability, automation, productivity, but also quality assurance, as comparatively visualized in detail in Kaspar et al. (2018). Set against this background, a 
prospective challenge lies in a holistic assessment and integrated selection of an appropriate manufacturing technology (production definition) bearing in mind a tailored geometrical design (product definition) along with a further optimized material definition. Finally, this is based on the individual application (e.g., requirements, load case, legitimate expenses) and ideally is already secured in the early product development phase.

Therefore, this contribution applies an integrated product and production engineering (IPPE) approach on the evaluation of when and under which conditions or rather technical, economic and ecological criteria AM is a worthwhile approach to be preferably used in comparison to conventional (formative and subtractive) technologies. Accordingly, and to share the actual state of the art in literature, first a short summary of different general as well as domain-specific assessment and selection approaches is given in Section 2. On this basis, Section 3 outlines the IPPE framework being further extended to an enhanced implementation and potential analysis of additive manufacturing technologies. Followed by an application example of conceptualizing a single-stage transmission to validate the novel early phase approach (Section 4), Section 5 finally discusses the findings and concludes by providing an outlook.

\section{State of the art}

Prior to the basic introduction of IPPE approach along with its graphical visualization of AM potentials, the following chapter reviews fundamental scientific approaches for (mostly) selecting product solutions, manufacturing technologies, and materials individually, but also with regard to a simultaneous development. Subsequently, a deeper view follows on contributions to evaluate/assess AM technologies.

\subsection{Selection of product solutions, manufacturing technologies, and materials}

The selection of product solutions, manufacturing technologies, and materials are crucial steps in product creation, since it massively determines the later success of the product as well as its sustainability. For this reason, a systematic approach that considers multiple criteria is inevitable.

A systematic strategy for the selection of product solutions is described in Pahl and Beitz (1996). Herein, the deployment of solution-neutral functions based on the requirements is the initial step. Alternative solutions for each function have to be developed, subsequently. Thus, methods like the morphological chart are able to support the developer by selecting the best solution. Accordingly, an objective assessment is required to reduce the negative impact of subjective influences on the design process. VDI (1998), for example, presents such an approach that assesses possible solutions on a 0 to 4 scale in terms of technical and economic values representing its qualitative fulfillment. Subsequently, both values are arranged in a diagram for each solution, wherein the developer can select the most promising solution. An extension of this approach to ecological values is an option to realize a multidimensional assessment.

Apart from that, the selection of materials and manufacturing technologies determines the technical, economic and ecological performance of a product to a high degree. However, narrowing potential materials and processes is a huge challenge for developers due to the high number of potential solutions, why Farag (2014) or Ashby (2011) provide approaches to support design engineers fundamentally. Referring to the latter and starting with the translation of material-related requirements into specific material properties, the material variety is screened by using constraints and material indices that describe the ratio between two properties. In doing so, the Cambridge Engineering Selector (CES) supports the screening and eliminating of potential materials with socalled material property charts. Subsequently, the remaining materials are ranked according to their performance, and finally are suggested specifically to be used on the singular material point of view. Moreover, and according to this deficit, this approach is extended towards a slightly similar but first integrated perspective of process selection by means of adequate process constraints in Ashby et al. (2004). In addition, Ashby (1991) integrates design-related aspects like possible (shape) geometries into the material selection process. However, a true concurrent selection is still missing until now. 


\subsection{Simultaneous engineering}

Simultaneous engineering (SE) is a well-known approach that focuses a parallel development of products and production systems. Initial approaches emerged already in 1969, although the topic achieved wide attention in science in the 1980s (Zhang and Zhang, 1995). Thus, reducing time and costs by a parallelization of tasks and better communication between product and production development constitute the main targets of simultaneous engineering (Wheelwright and Clark, 1992). Additionally, and according to Andreasen and Hein (1987), a deeper integration of methods and processes is required, instead of a simple integration of organizational units to face the challenges of distributed tasks in modern companies. As a result, the prestigious design for manufacturing and assembly (DfMA) integrates manufacturing aspects into product development (Boothroyd et al., 2002). Furthermore, the set-based concurrent engineering approach works with solution sets in product and production engineering that are systematically narrowed along the development process, but not totally eliminated until the end (Ward et al., 1994). This is because a greater flexibility concerning unexpected changes is still a resulting benefit, particularly to handle initial uncertainties within the early product development. In addition, and compared to the predecessors, Benders (2011) presents an approach that focuses material aspects explicitly within an integrated material, manufacturing process and geometry synthesis. Herein, the shape of all product parts are determined based on the working principle. Afterwards, potential manufacturing processes and materials are selected successively, and finally the solution combinations are assessed according to technical, economic and ecological criteria.

Based on the former literature review, the authors developed an integrated product and production engineering framework. Although this initial framework (Vielhaber and Stoffels, 2014) is basically focused on the two fundamental domains of product and production development, material selection as an essential part within engineering design is equally considered as a third domain in Stoffels et al. (2015) and Kaspar et al. (2016), as comparatively defined in Figure 1.

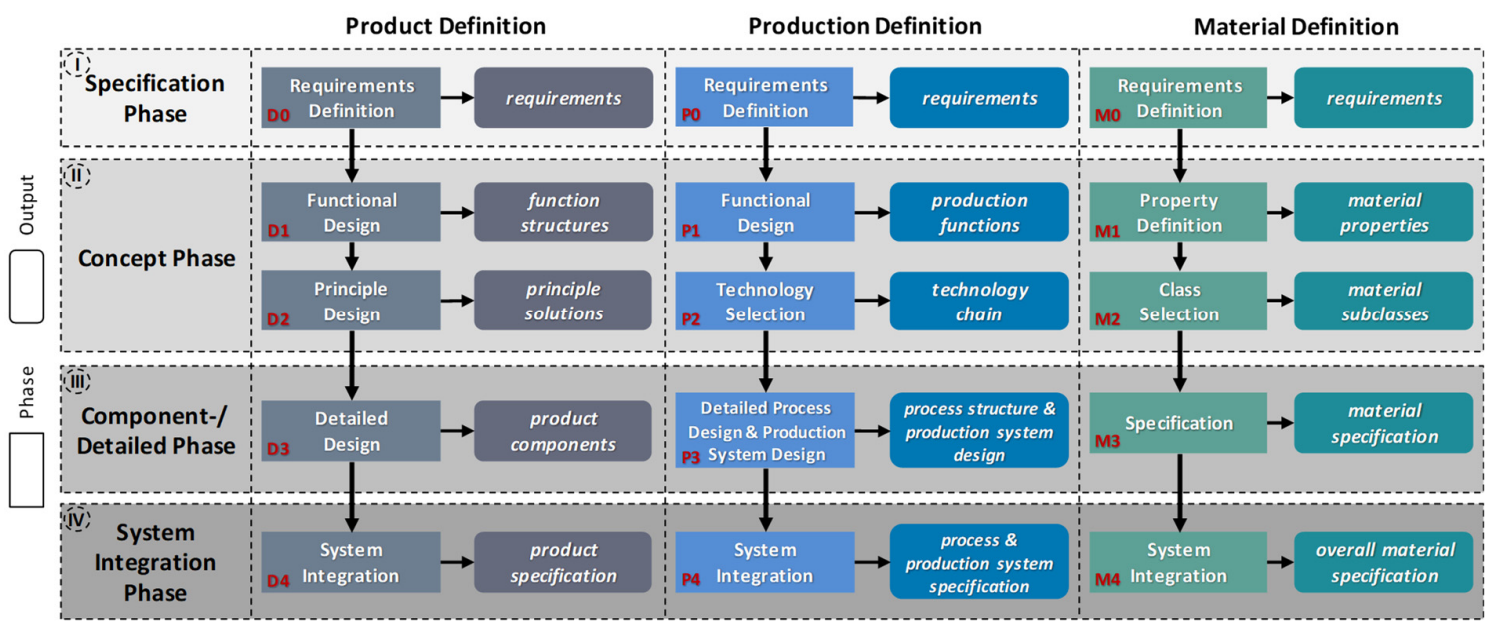

Figure 1. Comparison and classification of development phases and outputs of the integrated product, production and material engineering framework (Stoffels et al., 2018)

Herein, the process is divided into four phases in each domain. At first, the specification phase (I) determines all requirements, which are domain-specifically relevant. Afterwards, the two-part concept phase (II) develops promising engineering principles, initially based on fundamental material properties of a functional structure from a product and production point of view. The principle concepts are subsequently detailed on component level, including material specification as well as basic embodiment structure of process and plan design (component/detailed phase (III)). Finally, the system integration phase (IV) integrates all components of the entire system and, among others, evaluates the interplay. 


\subsection{Evaluation/assessment of AM potentials}

Beyond that, more and more approaches deal with the potentials of the highly revolutionizing process of AM throughout the different phases of the product development process. One the one hand, there are innumerable technological (e.g., individual parameter settings for particular materials and machine systems (Yakout et al., 2017)) and embodiment engineering strategies (e.g., fundamental design processes and methods (Emmelmann et al., 2011) along with specific design guidelines (Thomas, 2009; Adam and Zimmer, 2014; Kranz et al. 2015)). On the other hand, however, the amount of approaches implementing AM already in the early phase of product development (task clarification and conceptual design) is substantially reduced. But this lack in particular may lead to huge losses in product design from the very beginning, notably with regard to technical, economic and ecological aspects. Thus, current research activities are evaluated below, which aim at the utilization of AM technology for component design already on an early or rather abstract point of view.

Since additive manufacturing is currently not established as a standard manufacturing technology, different contributions provide a view on the potential implementation of AM within the manufacturing process chain, e.g., as proposed by Eyers and Potter (2017). Herein, the general evaluation of usability and potential analyses are presented in order to enhance decision-making processes for the design concept and component manufacture referring to different foundations. Hartogh and Vietor (2017), for example, present an approach that encourages a complexity-based decision-making process utilizing non-dimensional similarity coefficients including volume and surface portions of components, and thus allow to determine advantages or disadvantages in using AM for certain components.

Continued on a conceptual basis, and with respect to mechanical or rather geometrical aspects, AM processes open up opportunities for lightweight design and material efficiency in highly complex parts, which often cannot be manufactured using traditional technologies, as essentially stressed by Bikas et al. (2016) and Klahn et al. (2014). They indicate the ability to enforce cost savings by reducing material invest and profusion of whether powder or solid-bound materials used for powder-based or filamentbased technologies. Following the argumentation of Klahn et al. (2014), there is a need to identify parts that are likely to bear potential for an advanced functional integration, and therefore can be realized as "integrated design" parts. In fact, lightweight design enables significant advances concerning parts with high rotational moment of inertia and those parts responsible for transportation activities, whereby Klahn et al. (2014) highlight the importance of "efficient design" for those kinds of parts.

In addition, an often-emphasized point in additive manufacturing is the potential effect on cost savings for certain (small limited) lot sizes of manufactured parts. The consideration of production costs starts with its actual material and machine (investment) costs in general and continues in a full lifecycle assessment (LCA) of the part and its adjacent product system, which differentiates between direct and indirect costs (Cunningham et al., 2017). This includes overhead and administration costs on a timerelated basis and takes into account mandatory post-processing costs, which are partly based on timeconsuming manual work. Concerning this matter, Schröder et al. (2015) enhance a strategy to optimize the utilization of building space, part positioning and build direction as highly influencing factors for cost savings regarding post-processing activities.

Besides that, and considering environmental impacts of available AM processes, Yoon et al. (2014) compare the energy consumption in bulk forming, subtractive and additive processes illustrated by a case study. In contrast, Kellens et al. (2017) investigate the overall lifecycle inventory (LCI) for polymer and metal-based processes only and emphasizes a very high environmental impact due to nitrogen consumption, whereas Faludi et al. (2016) show that most of the environmental impact is due the operational energy consumption. However, the overall impact needs to be considered alongside the whole process chain, beginning with material generation and provision, through to machine operation and post-processing activities.

To sum up, the aforementioned research approaches treat mostly singular issues regarding technical, economic and ecological aspects, but, indeed, mostly neglect a direct and combined comparison to conventional manufacturing technologies already on an abstract point of view. Thus, a holistically true, comparative assessment of different AM processes and conventional technologies could not be traced in the early phase of product development, which is now dedicated below. 


\section{Integrated assessment and selection process}

Based on the aforementioned framework (for further details please refer to (Stoffels, 2017; Stoffels et al., 2018)), a general process model is presented regarding the integrated definition of product, production, and material, which additionally implements three integrated assessment and selection steps to holistically complement the engineering model (displayed in the left-hand upper corner). An illustrated excerpt of the first integrated assessment phase is shown in Figure 2.

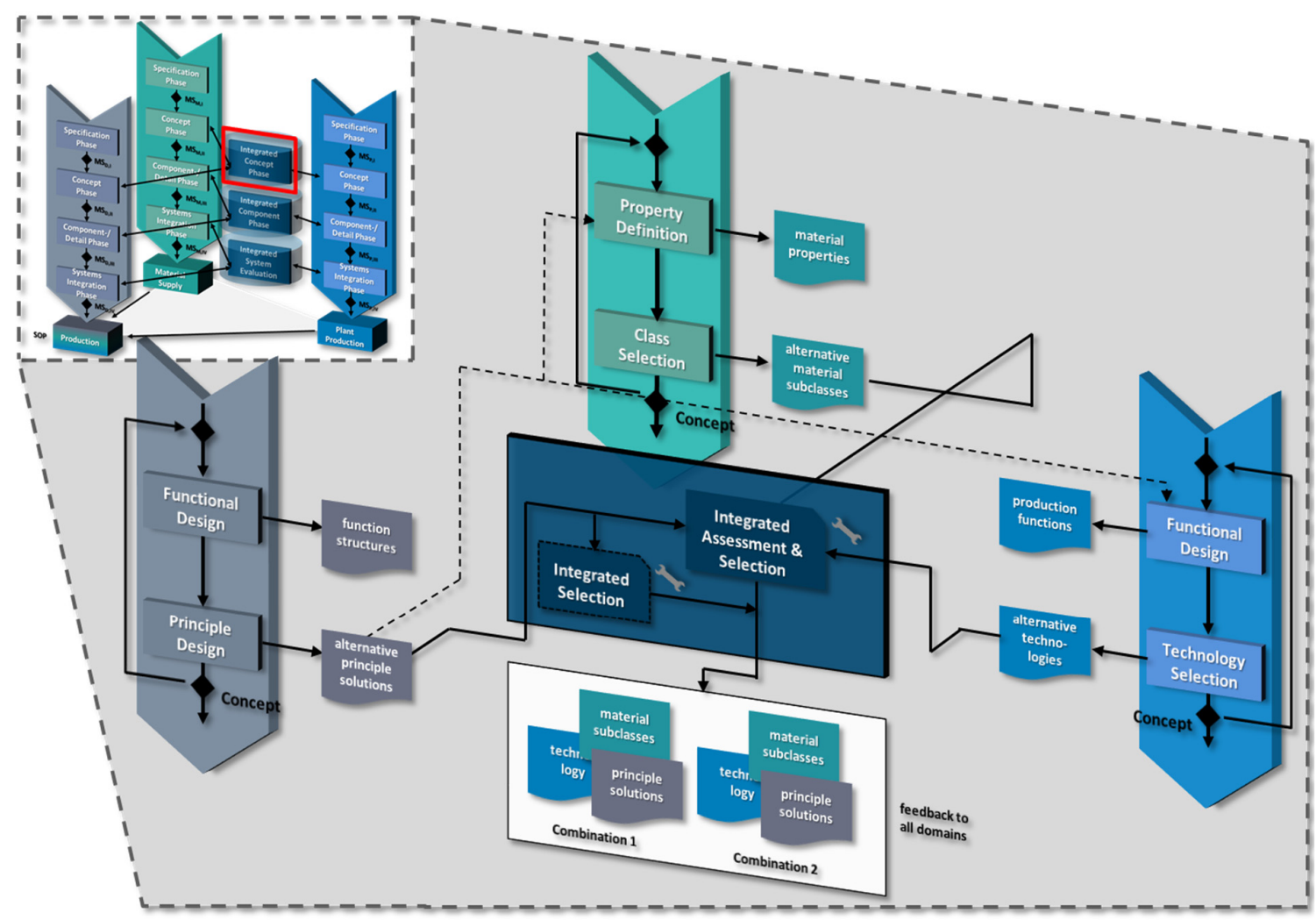

Figure 2. Detailed view on the first integrated phase of process model (Stoffels, 2017)

Beginning with the integrated concept phase (A), alternative combinations of working principles, manufacturing technologies and material subclasses are assessed and narrowed in face of technical (e.g., basic strength properties and corrosion resistance), economic and ecological (e.g., energy consumption) aspects. This is done, among others, by means of design catalogues (e.g., Roth, 1982), literature collections like the DIN 8580 regarding the choice of manufacturing technology and/or various (computational) databases (e.g., the material-based software tool Granta CES Selector and the LCA GaBi software). Thus, the normalized qualitative determination of technical value (values between 1 (poor) and 10 (good)) of one solution combination corresponds to the straightforward summation of the technical value of the working principle to fulfill the required function (e.g., depending on efficiency factor), as well as the chosen process chain and its depending material input (e.g., number of production stages or achievable manufacturing tolerances and surface properties). A corresponding (normalized) specification is done for the economic and ecological value, but slightly more with regard to a brief lifecycle analysis (material degradation, production, use, and end-of-life), i.e., a holistic consideration and comparative weighting of costs and environmental impacts of each phases along the lifecycle. Thus, and as collectively displayed in Figure 2, an initially optimized selection is executed in a set-based (ranked) way grounded on the previously generated working principles that fulfill the functions of the product as well as the equally deployed alternative technological (manufacturing and material) issues with respect to their individually determined requirements. 
Subsequently, and against the background of a continued tracking of second and third best performing solution combinations, the same procedure is applied on the component/detailed phase (III), and thus enables an individually deeper perspective on the assessment of more specific solutions on product design, process technology and material specification inside the integrated component phase (B). In accordance with this detailing, also the assessment structure is further refined. In case of the technical value, for example, discipline-specific simulation methods such as an FEA and CFD analysis (design view) or NC simulation (process view) are carried out to gain exhaustive information about the entire product lifecycle. Thus, also a detailed comparison of an environmental performance evaluation (e.g., via $\mathrm{GaBi}$ ) is enabled.

Completed by an integrated system analysis (C), finally the pre-set (set-based) component design is merged in view of a cross-component validation and verification of its highly interconnected correlations to an efficient product, process and material design, which is stated as an essential part of future product developments according to Kaspar and Vielhaber (2016).

\subsection{Methodical support for the IPPE framework}

To address this process model systematically, the method of an integrated morphological chart has been developed by the authors to handle technical, economic and ecological data of alternative combinations, e.g., of working principles, technologies, and material subclasses. Based on the traditional morphological chart by Zwicky (1989) and its overall engineering solution composition on concept level, this method is extended to corresponding production and material solutions in an integrated and systematically assessed way, as initially presented by Stoffels and Vielhaber (2015), see Figure 3.

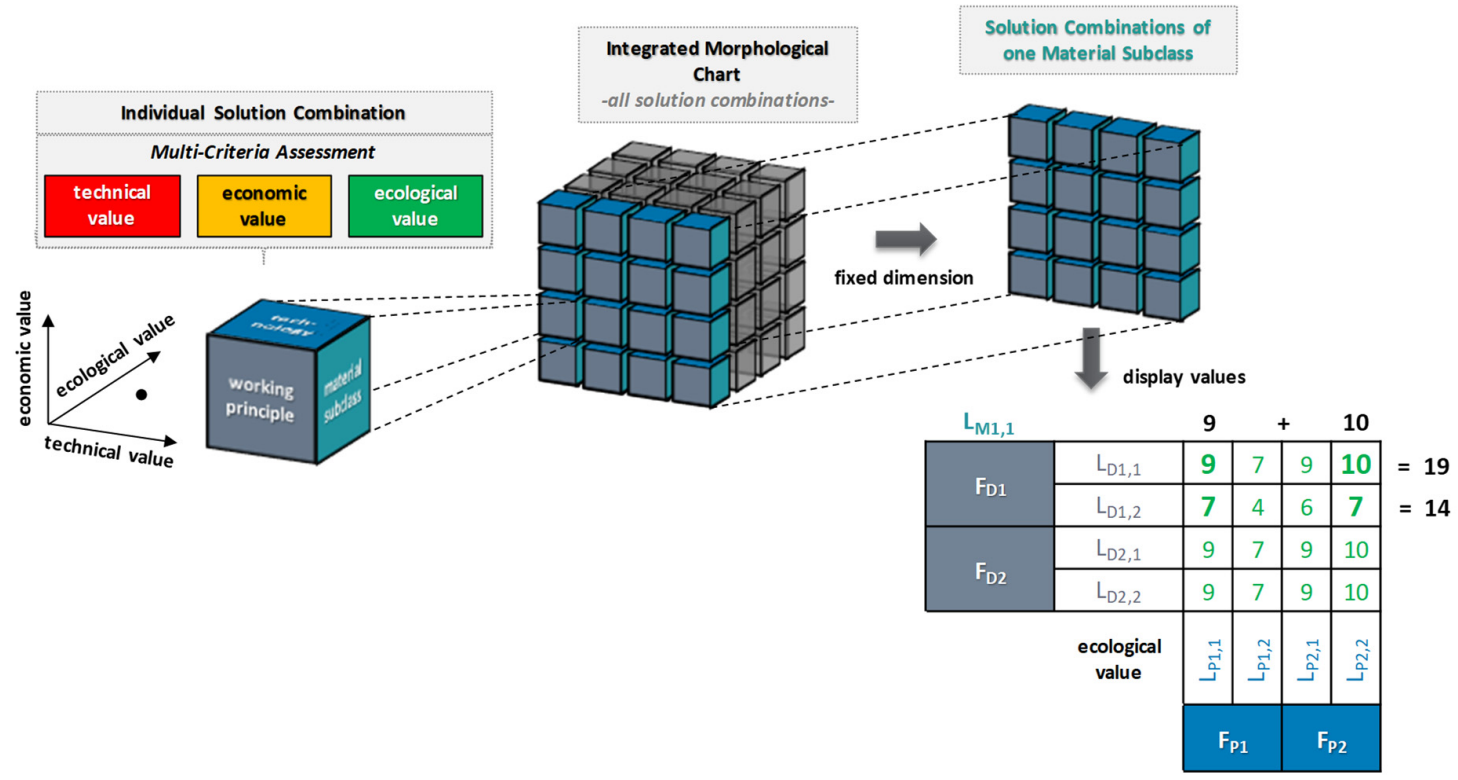

Figure 3. Illustrative procedure for the selection of solutions by the integrated morphological chart simplified for one fixed dimension, based on Stoffels (2017)

In doing so, the individual assessment is provided by the previously described aspects. Concerning this matter, and to deal with this quickly becoming complex issue in an even better way due to the six associated correlations (three assessment criteria and three potential solution sets), a three-dimensional cubic structure including several individual elements is needed.

Thus, the comprehensive cubic dice represents all combinations ordered by its hierarchically overarching functional structure on a product, production and material perspective, which, however, do not all have to be sensible or possible. In this way, each singular element constitutes one appropriate solution set with its individually assigned technical, economic and ecological values (1-10), whereas impossible combinations are marked with 0 , and not required production functions of a production chain (number of individual production functions) receive a technical value higher than 10 (casually13). 
In order to calculate the best performing solution combination to fulfill a necessary product function, now an extensive matrix-based approach is used. To clarify the calculation procedure in its basic form, at this point the material dimension is fixed, and thus complexity is visually reduced, as shown in Figure 3. For this purpose, first the production solutions $\left(\mathrm{L}_{\mathrm{P} ; \mathrm{i}, \mathrm{j}}\right)$ with the highest value are selected in each line within the production functions $\left(\mathrm{F}_{\mathrm{p} ; \mathrm{i}}\right)$. The sum of the best solution per production function represents the total value (e.g., $9+10=19$ vs. $7+7=14$, in case of Figure 3 ). Then, the product solution $\left(\mathrm{L}_{\mathrm{D} ; \mathrm{g}, \mathrm{h}}\right)$ with the highest total value is selected for each product function $\left(\mathrm{F}_{\mathrm{D} ; \mathrm{g}}\right)$. The results of the calculated selection are now ranked for the product solutions to fulfill the product function depending on the best production solutions required for the product chain functions. Subsequently, this procedure has to be carried out for all considered material subclasses or materials $\left(\mathrm{L}_{\mathrm{M} ; \mathrm{k}, \mathrm{l}}\right)$, which was seen as fixed in the first place. Then, finally, the assessment value of one criterion is determined for all solution combinations. Additionally, this procedure needs to be executed for the other (two) remaining criteria, which, however, will not further be calculated with another, and thus results in three different overall values with respect to a technical, economic and ecological performance (see Figure 6). Depending on the present scenario, even a different starting point can be defined. For example, if a new product should be developed on an already existing production system, the production functions can be derived from the existing product solutions, and thus finally the operating principles $\left(\mathrm{L}_{\mathrm{D} ; \mathrm{g}, \mathrm{h}}\right)$ can be sought that fulfill the production function and - in total - can be fabricated by the whole production chain functions.

Nevertheless, and as can be becoming increasingly evident for a development task with the many principle solutions as well as its related manufacturing processes and materials placed at the constructors disposal, manual evaluation quickly adopts a particularly intricate and interlinked structure. Consequently, an innovative software tool is coded based on an online analytical processing (OLAP) system used as a standardized solution for multidimensional analysis in economic computer science, see Figure 7. This efficiently prepares aggregated values for technically, economically and ecologically assessed data sets, which are individually stored in an SQL database and being calculated in advance (i.e., the choice of options on upper selection level already considers the possible selection options on a lower level). The general selection approach takes place hierarchically until all solutions of a combination have been selected, i.e., the user starts on a predefined start selection sequence (e.g., product function) and sequentially works through to the lowest selection level (e.g., material solution). To select an appropriate solution step-by-step on each function or solution level, there are two ways within the user interface to visualize the solution options. On the one hand, the user can manually select the combinations in a selected window based on the displayed, but individually weighted technical, economic and ecological performance with respect to each respective scenario, and on the other hand, the overall most valuable combination is automatically proposed first in a ranked list. In view of an improved visualization of the individually juxtaposed solution options, a three-dimensional Cartesian coordinate system is implemented to show the spatial location of the results freely rotatable. In doing so, also the change towards a two-dimensional view is possible to partly provide a better indication, for example, of a specific technical-economic valence. Anyway, this general build as well as its mentioned functions should not be illustrated separately at this point, but instead are represented directly associated with the application example at the end.

\subsection{Introduction of $A M$ within the integrated selection tool}

In conclusion, the integrated and set-based selection tool originating from the basic idea of an integrated morphological chart allows the systematic selection of solution combinations from a design, process and material point of view. This is successfully feasible for conventional manufacturing technologies and its common process chain (primary forming, reshaping, cutting, joining, coating, and/or altering the substance properties). However, including the emerging AM technologies to the comparative assessment and selection procedure, the production function and solution system needs to be reviewed due to the revolutionizing process workflow of AM and its extensive reduction of individually needed process steps within the continuous process chain design. This means that the basically required amount of process stages (forming, shaping, cutting, and joining) can be fundamentally reduced and substituted by only one "real" AM process step occasionally supplemented by an increased post-processing (see 
Figure 4), which automatically leads to an unequal value creation as a sum of its process chain design, but still has to be assessed comparatively.

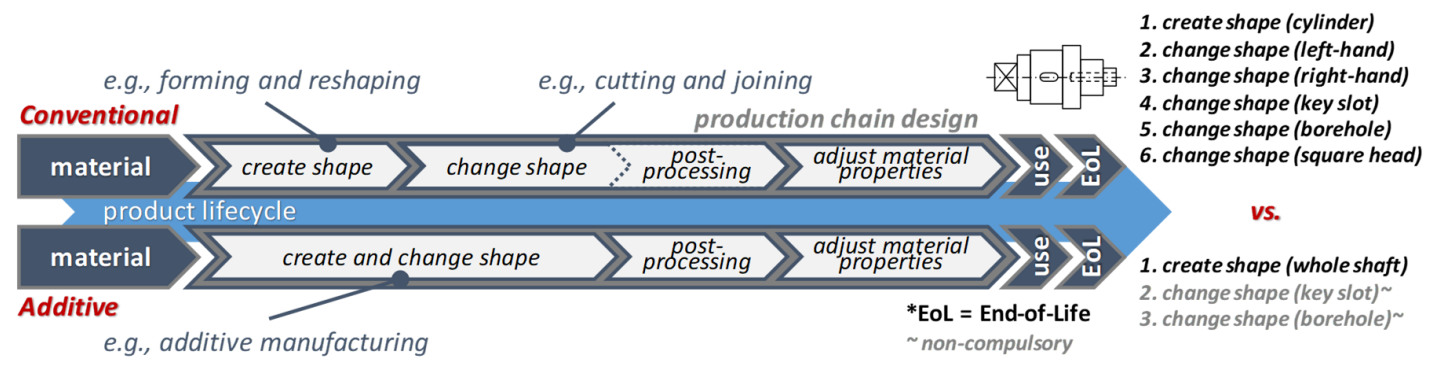

Figure 4. Comparative process chain design of conventional and additive manufactured components concerning its assessment

To deal with this challenge, the mostly mandatory process step of "post-processing" is classified to the sequence level of "change shape" shortly after a component is additively manufactured in terms of "create shape". Nonetheless, and with regard to a simplification of the overall process chain design, all unnecessary individual steps (e.g., a saved second change shape process) are technically valued with 13 (not necessary), i.e., in order of a magnitude higher than anything normally possible, which indicates the considerable savings. Thus, a comparative assessment takes place to support the product engineer already in an early phase of product development either the application of an additive manufacturing technology may be beneficial or not. In order to clarify the assumptions, Figure 4 exemplarily depicts a simplified shaft composed of the basic corpus, a square head, key slot, and borehole used to transmit torque and align the shaft axis with a cover. Herein, the AM process chain is significantly reduced compared to the conventional process, but still need to include some steps to assure the shaft's desired function (such as key slot and borehole creation). This procedure now is focused in more detail on an application example to directly get in the assessment and selection procedure as transparent as possible.

\section{Application example}

The integrated product and production framework provides an appropriate tool for the potential analysis of additive manufacturing technologies in the form of an integrated morphological chart. Therefore, the use of this method is evaluated by applying it to the simplified integrated conception of a single-stage electric drive gearbox of a formula student car, or rather more detailed of the function to transmit its torque. Hence, the first step contains the collection of data (list of requirements) and their corresponding selection of alternative principle solutions, production functions and technology solutions as well as derived material properties along with its subclasses, as shown in Figure 5.

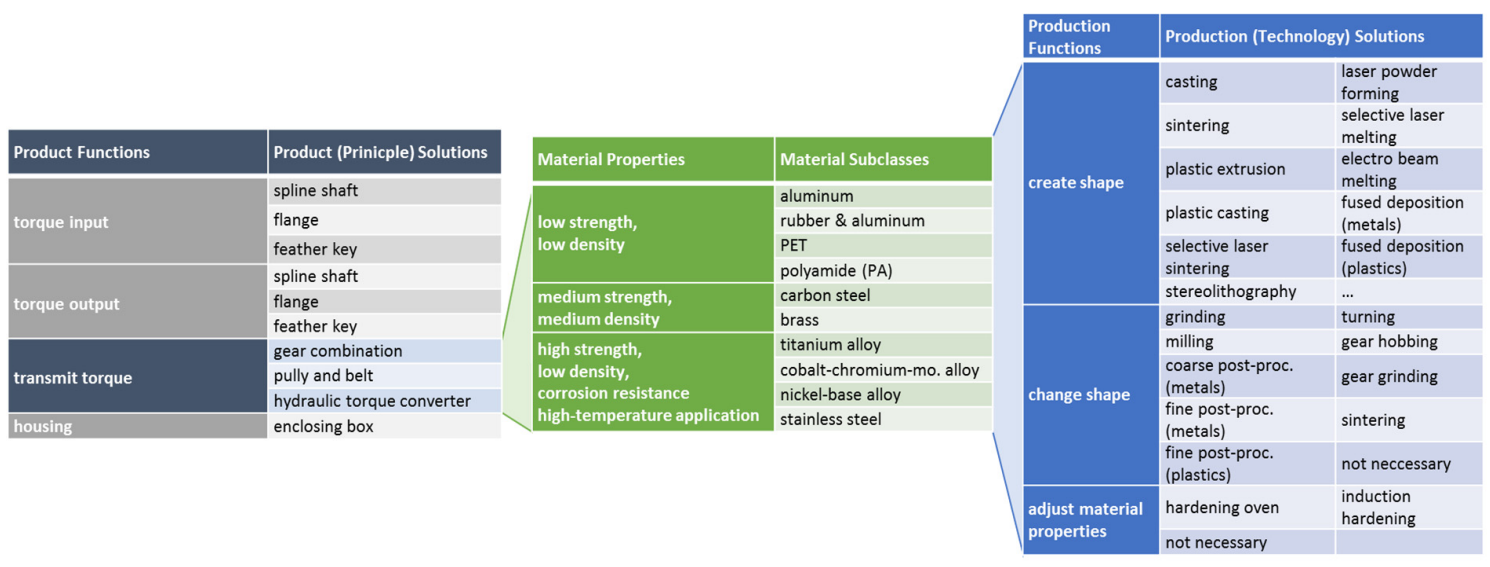

Figure 5. Selection tree of the simplified development of a single-stage gearbox 
Based on this selection tree, the three-dimensionally systematic assessment of individual combinations takes place (e.g., the technical, economic and ecological/environmental value of a gear combination to transmit torque (product function) made from stainless steel, as partly shown in Figure 6).

\begin{tabular}{|c|c|c|c|c|c|c|c|c|c|c|c|c|c|c|c|c|c|}
\hline & Weighting & & 0,1 & 0,1 & 0,1 & 0,1 & 0,2 & 0,3 & 0,05 & 0,05 & & 0,5 & 0,5 & & 0,25 & 0,25 & 0,5 \\
\hline \multirow[t]{2}{*}{ Mat.Solution } & Production Solution & ENV & $E_{M}$ & $\mathrm{CO}_{2 \mathrm{M}}$ & Crit. & MIPS & $E_{p}$ & $\mathrm{Eff}_{U}$ & $\mathrm{E}_{\text {Recy }}$ & $\mathrm{CO}_{2 \text { Recy }}$ & ECO & $\mathrm{C}_{\mathrm{M}}$ & $C_{p}$ & TEC & Func. & Proc. & Mat. \\
\hline & Create Shape & & & & & & & & & & & & & & & & \\
\hline Stainless Steel & Casting & 9 & 10 & 10 & 7 & 9 & 8 & 10 & 9 & 9 & 8 & 9 & 7 & 9 & 10 & 5 & 10 \\
\hline Stainless Steel & Fused Deposition (metal) & 9 & 10 & 10 & 7 & 9 & 5 & 10 & 9 & 9 & 7 & 9 & 5 & 9 & 10 & 5 & 10 \\
\hline Stainless Steel & Laser Powder Forming & 9 & 10 & 10 & 7 & 9 & 6 & 10 & 9 & 9 & 5 & 9 & 1 & 9 & 10 & 4 & 10 \\
\hline Stainless Steel & Selective Laser Melting & 9 & 10 & 10 & 7 & 9 & 6 & 10 & 9 & 9 & 5 & 9 & 1 & 10 & 10 & 8 & 10 \\
\hline$\ldots$ & $\ldots$ & & & & & & & & & & & & & & & & \\
\hline Stainless Steel & Turning & 9 & 10 & 10 & 7 & 9 & 8 & 10 & 9 & 9 & 9 & 9 & 9 & 8 & 10 & 1 & 10 \\
\hline Stainless Steel & Gear Grinding & 9 & 10 & 10 & 7 & 9 & 6 & 10 & 9 & 9 & 8 & 9 & 7 & 10 & 10 & 10 & 10 \\
\hline Stainless Steel & Coarse Post-Processing & 9 & 10 & 10 & 7 & 9 & 9 & 10 & 9 & 9 & 9 & 9 & 9 & 10 & 10 & 9 & 10 \\
\hline Stainless Steel & Sintering & 8 & 10 & 10 & 7 & 9 & 2 & 10 & 9 & 9 & 9 & 9 & 9 & 10 & 10 & 8 & 10 \\
\hline Stainless Steel & not necessary & 10 & 10 & 10 & 7 & 9 & 13 & 10 & 9 & 9 & 11 & 9 & 13 & 11 & 10 & 13 & 10 \\
\hline Stainless Steel & Hardening Oven & 9 & 10 & 10 & 7 & 9 & 5 & 10 & 9 & 9 & 10 & 9 & 10 & 10 & 10 & 10 & 10 \\
\hline Stainless Steel & Induction Hardening & 0 & 10 & 10 & 7 & 9 & 0 & 10 & 9 & 9 & 10 & 9 & 10 & 10 & 10 & 10 & 10 \\
\hline Stainless Steel & not necessary & 10 & 10 & 10 & 7 & 9 & 13 & 10 & 9 & 9 & 11 & 9 & 13 & 11 & 10 & 13 & 10 \\
\hline
\end{tabular}

\section{Figure 6. Excerpt of the assessment of solution combinations regarding the selected gear combination as product solution}

Once this is done, the aforementioned integrated software tool calculates the best solution combinations based on the selected product function (here: transmit torque), and thus issues aggregated final scores split into a separated technical, economic and ecological value. Subsequently, a sequential choice of solutions is available on each sequence level based on the suggested ranking or an individually preferred selection (weighting), which is now presented in Figure 7 for the choice of principle solutions (chosen gear combination) and the ensuing material subclasses (chosen stainless steel) to transmit the torque.

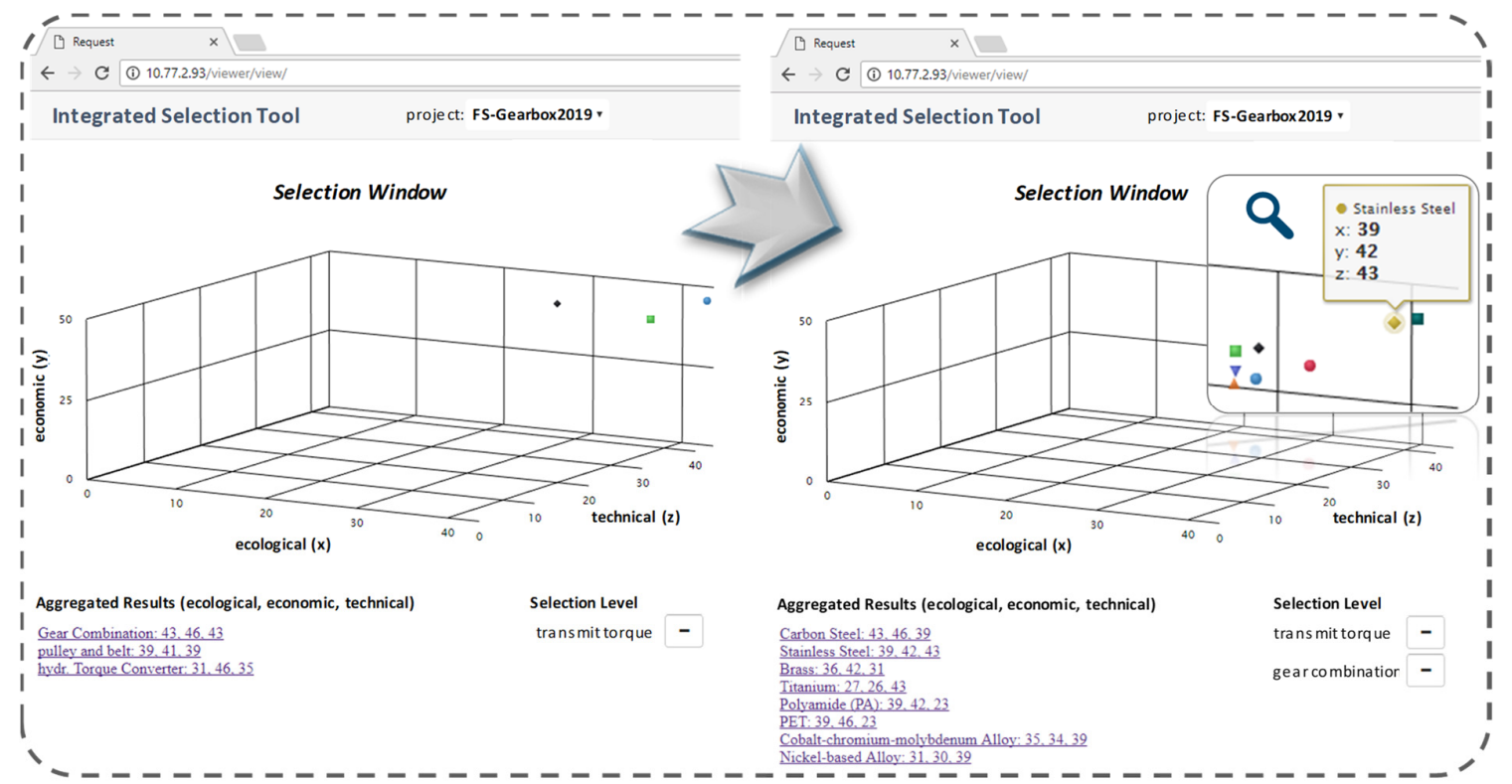

Figure 7. Selection of principle solutions and material subclasses to transmit the torque of a single-stage gearbox 
Then, and with regard to the chosen process to create the shape (conventional versus additive technologies), different process chain stages have to be completed. In case of the herein focused $(50 \%$ weighted) technical value and its previously selected solution of a stainless steel manufactured gear combination, the sintering and selective laser melting process set the most promising alternatives. Nonetheless, the underlying sequence structure varies. Whereas the sintering process needs a slightly more cost intensive gear hobbing or grinding process (change shape I) and fine post-processing (e.g., lapping or honing) as a second change shape process, selective laser melting is contented with a coarse and fine post-processing. Taking this into account, the sintering process with its downstream processes guarantees the best process chain solution for standard lot sizes. However, if there is no or just minor need for subsequent post-processing on the selective sintered part due to no functional adverse effects, the change shape I and II process can be omitted (i.e., marked as not necessary), and thus be competitive in comparison to the basic sintering process chain. This applies even apart from just small lot sizes or a technically adequate use of fused deposition modelling with metals and its downstream sintering process. Notwithstanding the foregoing, selective laser melting indicates the best process chain combination, since the fabricated system features a single-item production anyway, see Figure 8 .

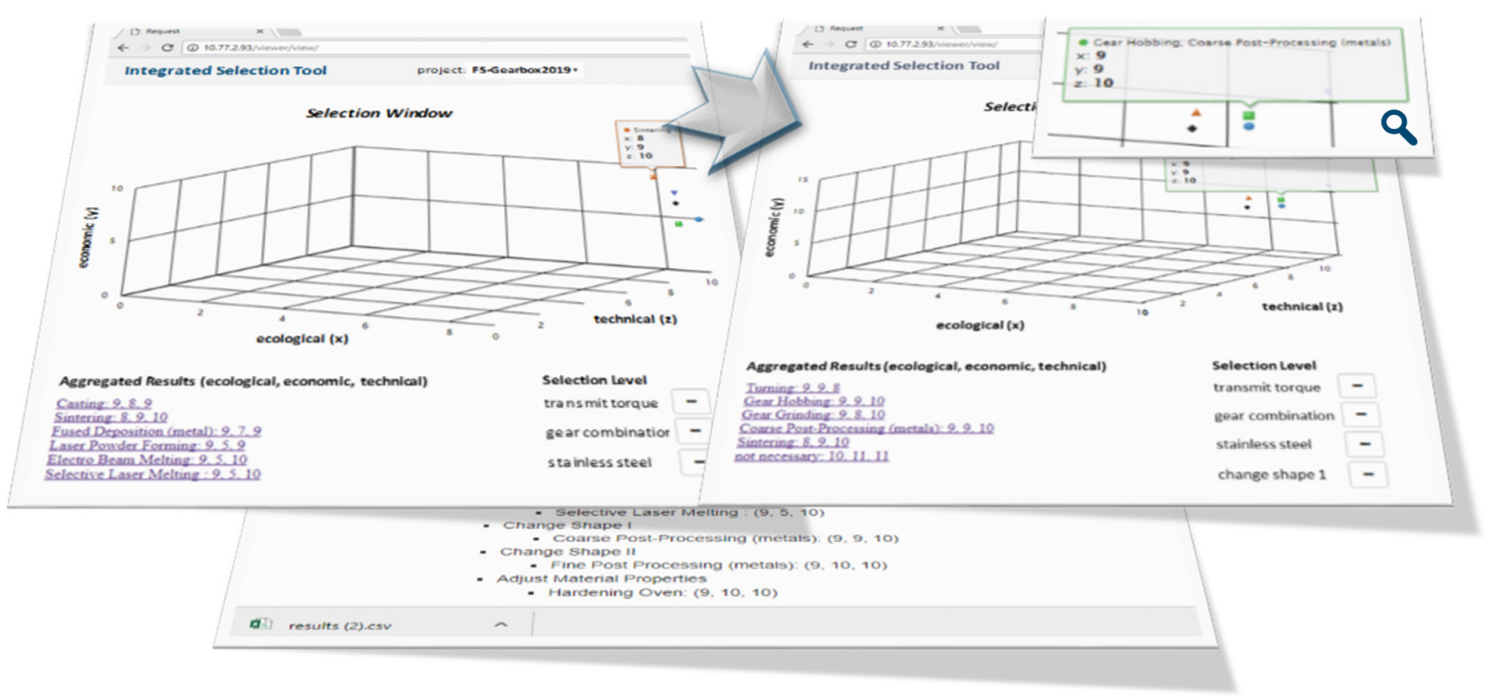

Figure 8. Process chain selection to transmit the torque of a single-stage gearbox

\section{Discussion and outlook}

Starting from a broad range of fundamental scientific approaches for (mostly) selecting product solutions, manufacturing technologies (including a deeper view on the evaluation/assessment of AM), and materials individually, this contribution stresses the need for a holistic and integrated product and production engineering (IPPE) approach with special regards to additive manufacturing. Thus, the integrated and set-based selection of the right production process bearing in mind a tailored geometry along with a further optimized material definition is supported by an adapted on-line analytical software tool based on the concept of an integrated morphological chart, which additionally takes into account a potential analysis of AM technologies already within the early phase of product development. In doing so, the methodological set-based approach provides a multi-criteria decision-making (MCDM) in terms of technical, economic and ecological aspects in an aggregated manner with respect to all relevant solution combinations (product design, process chain, and material).

In future work, the present database will be enhanced systematically in quality and quantity to deal with a larger variety of development tasks. At the same time, the concept will be lifted to a completely new level of cross-component (i.e., more systemic) aspects as an indispensable issue to increase the capability in terms of prospective multi-material lightweight systems (Kaspar and Vielhaber, 2016). Thus, also geometry specific aspects come to the fore. Moreover, a further processing is aimed to export the ranked list of alternatives directly to other concept tools (e.g., an integration possibility into SysML). 
However, this contribution already significantly adds value to an efficient and integrated choice of product, process, and material design on the bottom line, particularly with respect to the holistic implementation of the nowadays more and more demanded potential analysis of AM technologies.

\section{References}

Adam, G.A.O. and Zimmer, D. (2014), "Design for additive manufacturing - element transitions and aggregated structures", CIRP Journal of Manufacturing Science and Technology, Vol. 7 No. 1, pp. 20-28. https://doi.org/10.1016/j.cirpj.2013.10.001

Andreasen, M.M. and Hein, L. (1987), Integrated product development, IFS Publications, Bedfort.

Ashby, M.F. (1991), "Materials and shape", Acta Metallurgica et Materialia, Vol. 39 No. 6, pp. 1025-1039. https://doi.org/10.1016/0956-7151(91)90189-8

Ashby, M.F. (2011), Materials selection in mechanical design, Butterworth-Heinemann, Oxford.

Ashby, M.F., Brechet, Y.J.M., Cebon, D. and Salvo, L. (2004), "Selection strategies for materials and processes", Materials \& Design, Vol. 25 No. 1, pp. 51-67. https://doi.org/10.1016/S0261-3069(03)00159-6

Benders, M.J. (2011), Methodik der kombinierten Werkstoff-, Fertigungsverfahrens- und Geometriesynthese, $\mathrm{PhD}$ thesis, RWTH Aachen, Aachen.

Bikas, H., Stavridis, J., Stavropoulos, P. and Chryssolouris, G. (2016), "A design framework to replace conventional manufacturing processes with additive manufacturing for structural components: a formula student case study", Procedia CIRP 57 / 49th CIRP Conference on Manufacturing Systems, Stuttgart, Germany, May 25 - 27, 2016, Elsevier, Amsterdam, pp. 710-715. https://doi.org/10.1016/j.procir.2016.11.123

Boothroyd, G., Dewhurst, P. and Knight, W.A. (2002), Product design for manufacture and assembly, 2nd ed., Marcel Dekker, New York.

Bromberger, J. and Kelly, R. (2017), “Additive manufacturing: a long-term game changer for manufacturers”, In: Gambell, T. et al. (Eds.), The great re-make: manufacturing for modern times, McKinsey\&Company, New York, pp. 59-66.

Cunningham, C.R., Wikshåland, S., Xu, F., Kemakolam, N., Shokrani, A. et al. (2017), "Cost modelling and sensitivity analysis of wire and arc additive manufacturing", Procedia Manufacturing 11 / 27th International Conference on Flexible Automation and Intelligent Manufacturing, Modena, Italy, June 27 - 30, 2017, Elsevier, Amsterdam, pp. 650-657. https://doi.org/10.1016/j.promfg.2017.07.163

Emmelmann, C., Sander, P., Kranz, J. and Wycisk, E. (2011), "Laser additive manufacturing and bionics: redefining lightweight design", Physics Procedia 12 / LiM - Lasers in Manufacturing 2011, Munich, Germany, May 23 - 26, 2011, pp. 364-368. https://doi.org/10.1016/j.phpro.2011.03.046

Eyers, D.R. and Potter, A.T. (2017), "Industrial additive manufacturing: a manufacturing systems perspective", Computers in Industry, Vol. 92-93, pp. 208-218. https://doi.org/10.1016/j.compind.2017.08.002

Faludi, J., Baumers, M., Maskery, I. and Hague, R. (2016), "Environmental impacts of selective laser melting do printer, powder, or power dominate?", Journal of Industrial Ecology, Vol. 21 No. S1, pp. 144-156. https://doi.org/10.1111/jiec. 12528

Farag, M.M. (2014), Materials and process selection for engineering design, CRC Press, New York.

Gibson, I., Rosen, D.W. and Stucker, B. (2010), Additive manufacturing technologies: rapid prototyping to direct digital manufacturing, Springer, New York.

Hartogh, P. and Vietor, T. (2017), "Unterstützung des Entscheidungsprozesses in der Produktentwicklung additiv herzustellender Produkte mithilfe von Ähnlichkeitskennzahlen”, In: Lachmayer, R. and Lippert, R.B. (Eds.), Additive Manufacturing Quantifiziert, Springer Berlin, pp. 49-68. https://doi.org/10.1007/978-3-662-54113-5

Kaspar, J. and Vielhaber, M. (2016), "Cross-component systematic approach for lightweight and material-oriented design", Proceedings of NordDesign 2016, Trondheim, Norway, August 10-12, 2016, The Design Society, Glasgow, pp. 332-341.

Kaspar, J., Baehre, D. and Vielhaber, M. (2016), "Material selection based on a product and production engineering integration framework", Procedia CIRP 50 / 26th CIRP Design Conference, Stockholm, Sweden, June 15 - 17, 2016, Elsevier, Amsterdam, pp. 2-7. https://doi.org/10.1016/j.procir.2016.04.181

Kaspar, J., Stoffels, P., Schneberger, J.-H., Vielhaber, M. (2018), "Integrated product, production and material definition for conventional versus generative manufacturing technologies", Procedia CIRP / 28th CIRP Design Conference, May 23 - 25, 2018, Elsevier, Amsterdam, in press.

Kellens, K., Mertens, R., Paraskevas, D., Dewulf, W. and Duflou, J.R. (2017), "Environmental impact of additive manufacturing processes: does AM contribute to a more sustainable way of part manufacturing?", Procedia CIRP 61 / The 24th CIRP Conference on Life Cycle Engineering, Kamakura, Japan, March 08 - 10, 2017, Elsevier, Amsterdam, pp. 582-587. https://doi.org/10.1016/j.procir.2016.11.153 
Klahn, C., Leutenecker, B. and Meboldt, M. (2014), "Design for additive manufacturing - supporting the substitution of components in series production", Procedia CIRP 21 / 24th CIRP Design Conference, Milan, Italy, April 14 - 16, 2014, Elsevier, Amsterdam, pp. 138-143. https://doi.org/10.1016/j.procir.2014.03.145

Kranz, J., Herzog, D. and Emmelmann, C. (2015), "Design guidelines for laser additive manufacturing of lightweight structures in TiAl6V4", Journal of Laser Applications, Vol. 27 No. S1, pp. S14001. https://doi.org/10.2351/1.4885235

Pahl, G. and Beitz, W. (1996), Engineering design: a systematic approach, Springer, Berlin. https://doi.org/10.1007/978-1-4471-3581-4

Roth, K. (1982), Konstruieren mit Konstruktionskatalogen, Springer, Berlin. https://doi.org/10.1007/978-3-66208152-5

Schröder, M., Falk, B. and Schmitt, R. (2015), "Evaluation of cost structures of additive manufacturing processes using a new business model", Procedia CIRP 30 / 7 th International Product-Service Systems Conference, Saint Etienne, France, May $21 \quad$ - 22, 2015, Elsevier, Amsterdam, pp. 311-316. https://doi.org/10.1016/j.procir.2015.02.144

Stoffels, P. (2017), Integrierte Definition von Produkt, Produktion und Material zur Steigerung der Ressourceneffizienz, PhD thesis, Saarland University, Saarbruecken. https://doi.org/10.22028/D291-26985

Stoffels, P. and Vielhaber, M. (2015), "Methodical support for concurrent engineering across product and production (system) development", Proceedings of the 20th International Conference on Engineering Design (ICED 15), Milan, Italy, July 27 - 30, 2015, The Design Society, Glasgow, pp. 155-162.

Stoffels, P., Bähre, D., Frey, G. and Vielhaber, M. (2015), "Energy efficiency engineering - towards an integrated method framework for energy-oriented product and production development", 2nd International Congress on Energy Efficiency and Energy Related Materials (ENEFM2014), Springer Cham, pp. 291-297. https://doi.org/10.1007/978-3-319-16901-9_35

Stoffels, P., Kaspar, J., Bähre, D. and Vielhaber, M. (2018), "Integrated product and production engineering approach - a tool-based method for a holistic sustainable design, process and material selection", Procedia Manufacturing 21 / 15th Global Conference on Sustainable Manufacturing, Haifa, Israel, September 25 - 27 , 2017, Elsevier, Amsterdam, pp. 790-797. https://doi.org/10.1016/j.promfg.2018.02.185

The Economist (2012), The third industrial revolution: a 14-page special report, The Economist Newspaper Limited, London, pp. 1-14.

Thomas, D. (2009), The development of design rules for selective laser melting, $\mathrm{PhD}$ thesis, University of Wales Institute, Cardiff.

VDI (1998), VDI-Guideline 2225 Blatt 3: Konstruktionsmethodik - Technisch-wirtschaftliches Konstruieren Technisch-wirtschaftliche Bewertung, Beuth Verlag, Berlin.

Vielhaber, M. and Stoffels, P. (2014), "Product development vs. production development", Procedia CIRP $21 /$ 24th CIRP Design Conference, Milan, Italy, April 14 - 16, 2014, Elsevier, Amsterdam, pp. 252-257. https://doi.org/10.1016/j.procir.2014.03.141

Ward, A.C., Liker, J.K., Sobek, D.K. and Cristiano, J.J. (1994), "Set-based concurrent engineering and Toyota", Proceedings of Design Theory and Methodology, DTM'94 / 6th International Conference on Design Theory and Methodology, Minneapolis, United States, September 11 - 14, 1994, American Society of Mechanical Engineers, New York, pp. 79-90.

Wheelwright, S.C., Clark, K.B. (1992), Revolutionizing product development: quantum leaps in speed, efficiency and quality, The Free Press, New York.

Yakout, M., Cadamuro, A., Elbestawi, M.A. and Veldhuis, S.C. (2017), "The selection of process parameters in additive manufacturing for aerospace alloys", The International Journal of Advanced Manufacturing Technology, Vol. 92 No. 5-8, pp. 2081-2098. https://doi.org/10.1007/s00170-017-0280-7

Yoon, H.-S., Lee, J.-Y., Kim, H.-S., Kim, M.-S., Kim, E.-S., et al. (2014), “A comparison of energy consumption in bulk forming, subtractive, and additive processes: review and case study", International Journal of Precision Engineering and Manufacturing-Green Technology, Vol. 1 No. 3, pp. 261-279. https://doi.org/10.1007/s40684-014-0033-0

Zhang, H.C., Zhang, D. (1995), "Concurrent engineering: an overview from manufacturing engineering perspectives", Concurrent Engineering, Vol. 3 No. 3, pp. 221-236. https://doi.org/10.1177/1063293X9500300308

Zwicky, F. (1989), Entdecken, Erfinden, Forschen im morphologischen Weltbild, 2nd ed., Baeschlin, Glarus.

Jerome Kaspar, M.Sc.

Saarland University, Institute of Engineering Design

Campus E2 9, 66123 Saarbruecken, Germany

Email: kaspar@1kt.uni-saarland.de 